\title{
Proceeding
}

9th INSHS International Christmas Sport Scientific Conference, 4-6 December 2014. International Network of Sport and Health

Science. Szombathely, Hungary

\section{The role of spiral stabilization exercise on the level of postural stabilty}

\author{
IVAN STRUHÁR ${ }^{1} \triangle$, KATEŘINA KAPOUNKOVÁ ${ }^{1}$, TOMÁŠ VENCÚRIK ${ }^{2}$ \\ ${ }^{1}$ Faculty of Sport Studies, Department of Health Support, Masaryk University, Czech Republic \\ 2 2Faculty of Sport Studies, Department of Sports, Masaryk University, Czech Republic
}

\begin{abstract}
Struhár, I.,Kapounkova, K., \& Vencúrik, T. (2015). The role of spiral stabilization exercise on the level of postural stabilty. J. Hum. Sport Exerc., 9(Proc1), pp.S279-S285. The main aim of our study was to find out if exercise of spiral stabilization can improve level of postural stability (PS). PS is often described as the ability to maintain center of gravity within the base of support and it is also a fundamental part in assessing the efficacy of intervention for improving balance. Both, static and dynamic PS is the result of relationship between proprioception, vision and vestibular system. These three main sources are responsible for position of the body during static or dynamic activity. The participants were randomly divided into an experimental group (11 girls; mean age $=13.3 \pm 1.3$ years; mean height $=1.52 \pm 0.07 \mathrm{~m}$; mean body weight $=44.56 \pm 4.13 \mathrm{~kg}$ ) and control group (11 girls; mean age $=13.5 \pm 0.80$ years; mean height $=1.50 \pm 0.08$ $\mathrm{m}$; mean body weight $=46.45 \pm 6.27 \mathrm{~kg}$ ). At the beginning of the experiment, parents of participants signed the informed consent about participation on the programme. An electronic balance board was used for measuring PS. The exercise regimen was set up 4 times weekly for 3 months. The result of the study showed significant improvement in a level of postural stability in the experimental group (paired samples ttest; $p=0.00989$; the significance level $95 \%$ ) and there is no significant improvement in the control group $(p=0.25564$; the significance level $95 \%)$. Key words: BALANCE, PROPRIOCEPTION, SPINE
\end{abstract}

Corresponding author Ivan Struhár, Faculty of Sport Studies, Department of Health Support, Masaryk University, Kamenice 5, 62500 Brno, Czech Republic

E-mail: struhar@mail.muni.cz

9th INSHS International Christmas Sport Scientific Conference, 4-6 December 2014. International Network of Sport and

Health Science. Szombathely, Hungary.

JOURNAL OF HUMAN SPORT \& EXERCISE ISSN 1988-5202

(c) Faculty of Education. University of Alicante

doi:10.14198/jhse.2015.10.Proc1.15 


\section{INTRODUCTION}

The prevalence of sport injuries is especially high in a dance sport with muscle strains and sprains of the ankle and knee, anterior cruciate ligament injury and Achilles tendon pathology (Fulton, Burgi, Canizares, Sheets, \& Butler, 2014; Simon, Hall, \& Docherty, 2014). There is overwhelming evidence corroborating the notion that these types of problems do not only have a big impact in time lost from sport training and competition but also enhance costs of treatment. Sport-related injuries are related with mental problems which mean that they seriously affect future career of athletes (Roiger, Weidauer, \& Kern, 2015). The previous injuries are the biggest risk factors for new injuries and also alter kinematic chains or reduce range of motion (Waldén, Hägglund, \& Ekstrand, 2006). This fact was proved by several studies which investigated the effect of previous injuries as an important risk factor for future hamstring strain (Gabbe, Bennell, Finch, Wajswelner, \& Orchard, 2006; Sherry \& Best, 2004) or the recurrence of a secondary ankle sprain which follow after the same initial injury (Malliaropoulos, Ntessalen, Papacostas, Longo, \& Maffulli, 2009). The factors which can have a potential influence of injuries can be divided into intrinsic and extrinsic. Nowadays, it is a significant interest in the area of postural stability exercise as important part of elite sport with aim to optimizing performance and preventing injury. The effectiveness of preventing injuries was proved by several studies (Emery, Cassidy, Klassen, Rosychuk, \& Rowe, 2005; Holm et al., 2004; Arnold, Lanovaz, Oates, Craven, \& Butcher, 2015). The main aim of these programmes is improving ability to control the trunk and also to stabilize the spine when the sport activity is performed. A large variety of exercises can be found in a current literature but the application into a practice is problematic. Some investigators describe only balance exercises but in contrast, some authors often use the term neuromuscular training as a combination of balance, strength, plyometric exercises. It is a quite confusing because then it is impossible to differentiate which ones is more beneficial for athletes but some studies have already proved the impact of poor balance with regard to lower extremity injuries (McGuine, Greene, Best, \& Leverson, 2000; McKeon \& Hertel, 2008).

Studies to the same extent have already proved the importance of including postural stability exercise with aim to enhance proprioceptive input and kinesthetic awareness (Rasool \& George, 2007). Another problem of postural stability is the diversity of approaches to testing which often comes from the field of expertise. The kinematic characteristic of dancing requires a quick ability to switch from two to one leg standing position. In a general meaning, the lower and upper extremities are anatomically symmetrical across the sagittal plane (Grouios, Hatzitaki, Kollias, \& Koidou, 2009), but one of the bilateral extremity is always more preferred in a specific situation like turning or jumping from one leg etc. Subsequently, the inability to maintain single leg stance on the dominant side for certain period of time can indicate a higher risk of future injuries. Afterwards, testing single leg stance can provide basic information about predicting potential future injuries.

In our work, it was chosen the exercise with elastic cord (SM System) with aim of achieving muscle balance and improving coordination and balance. A person has to overcome a small resistance of elastic cord which can be adjusted during the exercise.

\section{MATERIAL AND METHODS}

\section{Participants}

Twenty-two healthy girls participated in this study. Before the participation in the study, all parents provided written informed consent and the rights of each participant were protected. Exclusion criteria included vestibular, neurological or orthopaedic disorders; medication causing a balance problem; an attendance 
rate of less than $90 \%$; not taking any kind of medication 16 hours prior of the measurements; any kind of experience with postural stability programme during the experiment.

All of the participants were elite dancers who had been training for 22 hours per week at the time of experiment. The sample was randomly assigned to a control group (11 girls; mean age $=13.5 \pm 0.80$ years; mean height=1.50 $\pm 0.08 \mathrm{~m}$; mean body weight= $46.45 \pm 6.27 \mathrm{~kg}$ ) and experimental group (11 girls; mean age $=13.3 \pm 1.3$ years; mean height=1.52 $\pm 0.07 \mathrm{~m}$; mean body weight $=44.56 \pm 4.13 \mathrm{~kg}$ ). Experimental group performed $4 \times 45$ minutes plus of exercise with elastic cord.

\section{Measures}

An electronic table (electronic balance board) with adjustable radius was used for measuring of the level of postural stability. This device provides wide anti-slip area $(42 \times 42 \mathrm{~cm})$ with three different oscillating radius $(5-12-20 \mathrm{~cm})$. The electronic balance board (EBB) is a medical device and it is compliant with Directive 93/42/EEC. The device enables to perform stability test and now it is also used for assessing ankle stability. Each result is expressed by number from 0 to 100 (100 is considered as the worst case and zero score is the best one; the whole score is created as a weighted average of area covered within the profile, outside the profile and recovery time). The level of postural stability was measured during barefoot standing on one leg on the EBB for 45 seconds (the dominant side was chosen by using simply test when the participant must run forward and jump up from one leg). The measurement of participants was before the intervention and after 3 months and it was also performed after regular dance training warm-up. The position of participant was precisely controlled during the testing on EBB (standing on either the left or right leg with opened eyes, keeping arms hanging freely by sides and balanced in medio-lateral position for 45 seconds as motionless as possible). The tilting part of EBB had a radius of $5 \mathrm{~cm}$ and participant got feedback from the screen. The measurement was started when participant had achieved stable single leg stance without intentional knee flexion and the participant got visual feedback about the result from the screen of computer. A test had to be stopped in case of 3 situations: 1. Participant changed the position of standing leg 2. A contralateral leg touched the floor 3. Participant started to use upper extremities for achieving balance.

\section{Procedures}

Participants in an experimental group took part in intervention programme by trained physical therapist. Each session of each week was undertaken under the supervision of author (IS) and each exercise and correct muscle contraction were demonstrated by physical therapist. The intervention programme was based on a compilation of published core-strengthening exercises, trunk stabilization exercises and rehabilitation protocols. The exercise protocol (5 exercises focused on dynamic stabilization and coordination) progressed from simple ones to complex (a balance mat was used from 4th week of intervention programme). The physical therapist focused on improving stability through motor control of deep trunk muscles with using elastic cord in experimental group.

The spiral stabilization exercise programme lasted 45 minutes during gymnastic training, 4 times a week for 3 months. Each participant and parents of participants was informed about health benefits of attending in programme. In total, the intervention programme included 5 exercises that focused on dynamic stabilization and coordination. 


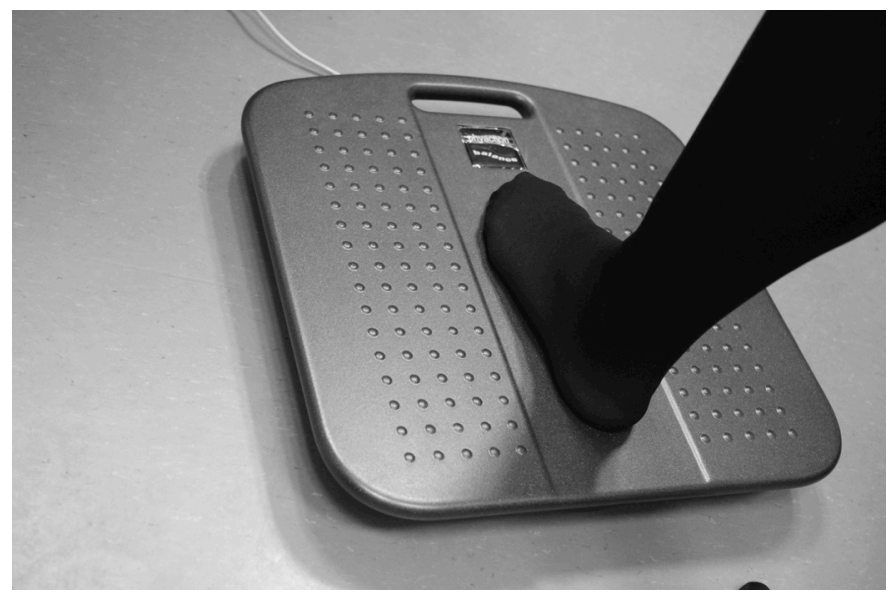

Figure 1. Electronic balance board

\section{Exercise protocol:}

\section{Exercise 1:}

Participant stands turned toward elastic cord with palms of upper extremities facing down (upper extremities remain extended by the elastic cord). Following this, participant performs isometric contractions of gluteal region with pulling the shoulder blade back and down (the palms are rotated upwards). Lastly, participant lifts one heel from the floor and waits for 6 seconds. Participants perform 4 sets of 12 repetitions for each side of the body.

\section{Exercise 2:}

Participant stands turned toward elastic cord. Subsequently, participant raises upper extremities as far as it goes towards fixed point of elastic cord and looks down (a chin is tucked toward the breastbone). Simultaneously, the participant starts to slowly bend the chest towards the pelvis but without moving of upper extremities. Participants perform 4 sets of 10 repetitions.

\section{Exercise 3:}

Participant starts in single-leg stance position with standing on one end of elastic cord. Then, participant holds the other end of the cord and starts to externally rotate the shoulder as far as comfortable with keeping $90^{\circ}$ flexed elbow. Participant performs 3 sets of 12 repetitions for each side of the body.

\section{Exercise 4:}

Participant kneels on the knee of a back leg and a front leg is extended forward. After, participant starts to roll down vertebra by vertebra towards to the extended leg (participant remains in this position for 10 seconds and then align the chest vertebra by vertebra to the starting position). Participants perform 5 sets of 10 repetitions for each side of body.

\section{Exercise 5:}

Participant stands turned toward elastic cord with chest bending downwards and upper extremities are crossed. Following this, the shoulder blades are pulled together, backward and downward as much as possible with rotating palms of upper extremities upwards. Participants perform 5 sets of 10 repetitions. (Smíšek, Smíšková, \& Smíšková, 2009). 
Analysis

Data are expressed as the mean \pm standard deviation (SD). Analyses were conducted using programme Statistica 12.0 and include descriptive statistics. The statistical significance was set at $p<0.05$.

\section{RESULTS}

Table 1. Descriptive statistic of participants

\begin{tabular}{lcccccc}
\hline & \multicolumn{2}{c}{ Age (years) } & \multicolumn{2}{c}{ Height $(\mathrm{m})$} & \multicolumn{2}{c}{ Weight $(\mathrm{kg})$} \\
\cline { 2 - 7 } Participant group & Mean & SD & Mean & SD & Mean & SD \\
\hline Experimental $(n=11)$ & $\# \# \#$ & $\# \# \#$ & ene-52 & 0,07 & 44,56 & abr-13 \\
Control $(n=11)$ & $\# \# \#$ & 0,8 & $\# \# \#$ & 0,08 & 46,45 & jun-27 \\
\hline
\end{tabular}

Firstly, we controlled the homogeneity of the groups (an independent t-test was used, $p=0.365944$ ). According to this result, the null hypothesis was not rejected and the both groups are homogenous. Electronic table (electronic balance board) with adjustable radius was used for measuring of the level of postural stability. A mean score of participants (Table 2) decreased in experimental group (pre-test $39.57 \pm 3.50$; post-test $34.32 \pm 4.32$ ) which has statistical significance but the mean score of participants in control group (Table 2) was risen (pre-test 39.12 \pm 2.72 ; post-test 39.91 \pm 2.62 ).

Table 2. The overall score of participants on the balance board

\begin{tabular}{lcc}
\hline Participant group & Pre-test & Post-test \\
\hline Experimental $(n=11)$ & $39.57 \pm 3.50$ & $34.32 \pm 4.32$ \\
\hline Control $(n=11)$ & $39.12 \pm 2.72$ & $39.91 \pm 2.62$ \\
\hline
\end{tabular}

We used effect size by Cohen's $d$ in view of finding the magnitude of differences between pre-test and post-test in the experimental group ( $\mathrm{d}=1.4142$ which indicates a large effect).

\section{DISCUSSION}

The study sought to identify if the exercise of spiral stabilization would result in improving postural stability when provided over a 3 months programme with elite dancers. In our study, it was hypothesized that intervention programme which was conducted in experimental group would have improved the level of postural stability measured by electronic balance board. The results pointed out that mean score of participants in the experimental group was significantly lower after the intervention programme $(34.32 \pm 4.32$ vs. $39.57 \pm 3.50)$ than the mean score in the control group $(39.91 \pm 2.62$ vs. $39.12 \pm 2.72)$. For better understanding full impact of intervention programme, we calculated the effect size by Cohen's $d$ in the experimental group ( $d=1.4142$ which indicates a large effect).

In regards to generalize of our findings, we noted that the participants of our study were elite dancers and they were all healthy and physically active at the time of experiment. Another problem is the diversity of approaches to testing. The most frequent way of assessment static and dynamic postural stability is testing with a force plate. The interest of investigators is often focused on centre of pressure (COP), measuring 
time to stabilization and often is emphasized COP speed as a characteristic to indicate steadiness of standing posture. In recent years, it has been used the star excursion balance test to identify dynamic postural stability and to predict the risk of lower extremity injuries.

In addition, some authors point out to different results in group of subject with ankle instability (Hertel \& Olmsted-Kramer, 2007; McKeon et al., 2008) and it also must be taken into consideration conditions of testing (eyes open and closed). In our work, it was chosen electronic balance board with adjustable radius to measure postural stability. We worked with a small number of participants to generalize the results for all dancers. Another limitation of the study is testing only preferred leg. The foregoing limitations imply that the future aim is to use similar programme with aim to compare results of testing on left/right leg.

\section{CONCLUSIONS}

This study is an attempt to emphasize the importance of including postural stability exercise into sports training as a necessary part of prevention sport-related injuries. The results showed that $4 \times 45$ minutes plus of exercise with elastic cord for 3 months period may improve postural stability.

\section{ACKNOWLEDGEMENT}

This paper was written at Masaryk university as part of the project "Monitoring of foot loading, body posture in relation to SM - System exercise for pupils of dance conservatoire" number MUNI/A/0854/2013 with the support of the Specific University Research Grant, as provided by the Ministry of Education, Youth and Sports of the Czech Republic in the year 2014.

\section{REFERENCES}

1. Arnold, C., Lanovaz, J., Oates, A., Craven, B., \& Butcher, S. (2015). The effect of adding core stability training to a standard balance exercise program on sit to stand performance in older adults: a pilot study. Journal of Aging and Physical Activity, 23(1), pp.95-102.

2. Emery, C. A., Cassidy, J. D., Klassen, T. P., Rosychuk, R. J., \& Rowe, B. H. (2005). Effectiveness of a home-based balance-training program in reducing sports-related injuries among healthy adolescents: a cluster randomized controlled trial. CMAJ: Canadian Medical Association Journal = Journal de l'Association Medicale Canadienne, 172(6), pp.749-754.

3. Fulton, J., Burgi, C., Canizares, R. C., Sheets, C., \& Butler, R. J. (2014). Injuries Presenting to a Walk-in Clinic at a Summer Dance Intensive Program: A Three-Year Retrospective Data Analysis. Journal of Dance Medicine \& Science: Official Publication of the International Association for Dance Medicine \& Science, 18(3), pp.131-135.

4. Gabbe, B. J., Bennell, K. L., Finch, C. F., Wajswelner, H., \& Orchard, J. W. (2006). Predictors of hamstring injury at the elite level of Australian football. Scandinavian Journal of Medicine \& Science in Sports, 16(1), pp.7-13.

5. Grouios, G., Hatzitaki, V., Kollias, N., \& Koidou, I. (2009). Investigating the stabilising and mobilising features of footedness. Laterality, 14(4), pp.362-380. doi:10.1080/13576500802434965

6. Hertel, J., \& Olmsted-Kramer, L. C. (2007). Deficits in time-to-boundary measures of postural control with chronic ankle instability. Gait \& Posture, 25(1), pp.33-39.

7. Holm, I., Fosdahl, M. A., Friis, A., Risberg, M. A., Myklebust, G., \& Steen, H. (2004). Effect of neuromuscular training on proprioception, balance, muscle strength, and lower limb function in 
female team handball players. Clinical Journal of Sport Medicine: Official Journal of the Canadian Academy of Sport Medicine, 14(2), pp.88-94.

8. Malliaropoulos, N., Ntessalen, M., Papacostas, E., Longo, U. G., \& Maffulli, N. (2009). Reinjury after acute lateral ankle sprains in elite track and field athletes. The American Journal of Sports Medicine, 37(9), pp.1755-1761.

9. McGuine, T. A., Greene, J. J., Best, T., \& Leverson, G. (2000). Balance as a predictor of ankle injuries in high school basketball players. Clinical Journal of Sport Medicine: Official Journal of the Canadian Academy of Sport Medicine, 10(4), pp.239-244.

10. McKeon, P. O., \& Hertel, J. (2008). Systematic review of postural control and lateral ankle instability, part II: is balance training clinically effective? Journal of Athletic Training, 43(3), pp.305315.

11. McKeon, P. O., Ingersoll, C. D., Kerrigan, D. C., Saliba, E., Bennett, B. C., \& Hertel, J. (2008). Balance training improves function and postural control in those with chronic ankle instability. Medicine and Science in Sports and Exercise, 40(10), pp.1810-1819.

12. Rasool, J., \& George, K. (2007). The impact of single-leg dynamic balance training on dynamic stability. Physical Therapy in Sport, 8(4), pp.177-184.

13. Roiger, T., Weidauer, L., \& Kern, B. (2015). A Longitudinal Pilot Study of Depressive Symptoms in Concussed and Injured/Nonconcussed National Collegiate Athletic Association Division I StudentAthletes. Journal of Athletic Training.

14. Reilly, T., \& Gilbourne, D. (2003). Science and football: a review of applied research in the football codes. J Sport Sci, 21(9), pp.693-705.

15. Sherry, M. A., \& Best, T. M. (2004). A comparison of 2 rehabilitation programs in the treatment of acute hamstring strains. The Journal of Orthopaedic and Sports Physical Therapy, 34(3), pp.116125.

16. Simon, J., Hall, E., \& Docherty, C. (2014). Prevalence of chronic ankle instability and associated symptoms in university dance majors: an exploratory study. Journal of Dance Medicine \& Science: Official Publication of the International Association for Dance Medicine \& Science, 18(4), pp.178184.

17. Smí̌ek, R., Smí̌ková, K., \& Smí̌ková, Z. (2009). Spirální stabilizace: 12 základních cvikủ: léčba a prevence bolestí zad metodou SM-systém: funkčni stabilizace a mobilizace páteře. (149 s.) Praha: R. Smíšek.

18. Waldén, M., Hägglund, M., \& Ekstrand, J. (2006). High risk of new knee injury in elite footballers with previous anterior cruciate ligament injury. British Journal of Sports Medicine, 40(2), pp.158162; discussion pp.158-162. 